\title{
Sports participation with arachnoid cysts
}

\author{
Jennifer Strahle, MD, Béla J. Selzer, NP, Ndi Geh, BS, MSCR, Dushyanth Srinivasan, BA, \\ MaryKathryn Strahle, BS, Meleine Martinez-Sosa, MD, Karin M. Muraszko, MD, \\ Hugh J. L. Garton, MD, MHSc, and Cormac O. Maher, MD
}

Department of Neurosurgery, University of Michigan, Ann Arbor, Michigan

OBJECTIVE There is currently no consensus on the safety of sports participation for patients with an intracranial arachnoid cyst (AC). The authors' goal was to define the risk of sports participation for children with this imaging finding.

METHODS A survey was prospectively administered to 185 patients with ACs during a 46-month period at a single institution. Cyst size and location, treatment, sports participation, and any injuries were recorded. Eighty patients completed at least 1 subsequent survey following their initial entry into the registry, and these patients were included in a prospective registry with a mean prospective follow-up interval of $15.9 \pm 8.8$ months.

RESULTS A total 112 patients with ACs participated in 261 sports for a cumulative duration of 4410 months or 1470 seasons. Of these, 94 patients participated in 190 contact sports for a cumulative duration of 2818 months or 939 seasons. There were no serious or catastrophic neurological injuries. Two patients presented with symptomatic subdural hygromas following minor sports injuries. In the prospective cohort, there were no neurological injuries

CONCLUSIONS Permanent or catastrophic neurological injuries are very unusual in AC patients who participate in athletic activities. In most cases, sports participation by these patients is safe.

http://thejns.org/doi/abs/10.3171/2015.7.PEDS15189

KEY WORDS arachnoid cyst; concussion; incidence; injury; safety; sports; congenital

$\mathrm{I}$ NTRACRANIAL arachnoid cysts (ACs) are a common reason for neurosurgical referral. In our experience, one of the most pressing concerns of patients and their parents during these encounters has been to obtain a recommendation for a level of sports participation that may be considered safe. There is currently no consensus on the safety of sports participation for patients with ACs. For the past 4 years, we have systematically surveyed patients in our practice, determining their sports participation and sports-related injuries, and now report on a large registry of patients with ACs who have participated in sports. Our goal was to define the risk of athletic participation for patients with AC.

\section{Methods}

This study was approved by the University of Michigan Institutional Review Board. Beginning in December 2010, we prospectively administered a survey to all patients with a diagnosis of intracranial AC seen in the pediatric neuro- surgery clinic at the University of Michigan. We recorded demographic, treatment, imaging, and sports participation information for each individual. Demographic information included name, date of birth, and date of AC diagnosis. It is our practice to obtain axial images of the cyst at the time of the clinic consultation. Imaging information included location and size of the AC and any associated finding such as subdural hygroma. Recorded sports information included type of sport, level of sport activity, dates and duration of participation, and details on any sports injury that occurred. Additional information on any surgical treatment was gathered from the medical record. We made a distinction between participation at a junior level and high school varsity or higher level. Following the American Academy of Pediatrics classification of sports according to degree of contact, we considered baseball, basketball, dodgeball, football, hockey, lacrosse, martial arts, rugby, soccer, softball, ultimate Frisbee, water polo, and wrestling to be contact sports. ${ }^{54}$ All other sports were considered noncon- 
tact sports. Details of each sports injury were recorded. Sport participation was recorded according to number of months and number of seasons. A season was defined as a 3-month period for the purpose of this analysis. Patients for whom a survey was not completed during their clinic visit were contacted by telephone to complete the survey. Some patients were evaluated on more than one clinical encounter. These patients completed a survey at the time of each encounter. All sports activities that occurred prior to the first encounter were considered retrospective and those that occurred between the first and any subsequent survey were considered prospective.

In general, our practice has been permissive with respect to sports participation for patients with an AC. We have a detailed discussion with the patient and family regarding the potential risks and benefits of sports participation for each individual patient but do not proscribe any activity.

SAS software version 9.4 (SAS Institute) and Microsoft Excel (Microsoft Corp.) were used for data analysis. Injury rates were calculated using injury events as a numerator and seasons of sports participation as a denominator. Concussion incidence rates were calculated for all sports and contact sports.

\section{Results}

One hundred ninety-four patients with AC presented to the pediatric neurosurgery clinic at the University of Michigan from December 2010 to October 2014. A sports participation survey was obtained for 185 patients. Of the 112 patients who participated in sports, 34 were females and 78 were males. In the entire cohort, a total of 4410 months of sports participation or 1470 seasons of sports participation were recorded (Fig. 1; Table 1). Ninety-four patients (73 males and 21 females) played 190 contact sports, with 2818 months or 939 seasons of sports participation. The mean age at diagnosis was $7.8 \pm 5.6$ years for all patients surveyed and $9.9 \pm 5.3$ years for those who participated in sports. The mean age at the time of survey administration was $9.7 \pm 5.5$ years for all patients, $12.2 \pm$ 4.2 years for those who participated in sports, and $12.1 \pm$ 4.1 years for those who participated in contact sports. The mean AC size was $42.5 \pm 26.1 \mathrm{~mm}$ in maximum dimension for all patients and $45.9 \pm 25.9 \mathrm{~mm}$ for those who participated in sports. Middle fossa cysts were most common $(\mathrm{n}=82 ; 44 \%)$, followed by posterior fossa cysts $(\mathrm{n}=$ $49 ; 26 \%)$, quadrigeminal or ambient cistern cysts $(\mathrm{n}=19$; $10 \%)$, cerebellopontine angle cysts $(\mathrm{n}=14 ; 8 \%)$, cerebral convexity cysts $(n=13 ; 7 \%)$, anterior fossa cysts $(n=10$; $5 \%)$, suprasellar cysts $(\mathrm{n}=6 ; 3 \%)$, and interhemispheric cysts $(\mathrm{n}=1 ; 1 \%)$ (Fig. 2$)$.

Twenty-seven (15\%) of the 185 patients surveyed were treated surgically for their AC. There was no significant difference in patient age $(\mathrm{p}=0.44)$ or cyst location $(\mathrm{p}=$ 0.09 ) between those patients treated surgically and those treated nonsurgically. The mean age at the time of survey for surgically treated patients was 11.5 years \pm 4.4 years. There was no difference in sports participation between those treated surgically and those treated nonsurgically $(p=0.18)$. Eighteen of the surgically treated patients par- ticipated in sports postoperatively. There were no concussions and no other neurological injuries in this small group of patients.

There were 18 patients with sports-related concussions in the registry, and 4 patients had more than 1 concussion. Concussions occurred most frequently during football (n $=9)$ and soccer $(\mathrm{n}=3)$. Concussions were more likely to occur in contact sports, with a rate of 17/1000 seasons compared with 12/1000 seasons for all sports. Concussions were also more likely to occur in older patients. In this analysis, there were 51 patients who participated in any sport after the age of 13 (mean age $15.9 \pm 2.4$ years), and 23 patients who were at least age 13 years at time of the survey and had participated in a contact sport at a high school level (mean age $16.5 \pm 2.8$ years). Ten of these patients who had participated in contact sports at a high school level had experienced a sports-related concussion $(10 / 23 ; 43 \%)$.

No patients suffered a permanent neurological injury or injury requiring surgical treatment $(0$ injuries/1470 seasons; 95\% CI $0.00-0.25 \%){ }^{68}$ Two patients had neurological symptoms and imaging changes that were considered diagnostic for AC-related injury other than concussion during sports participation (2 injuries/1470 seasons; $95 \%$ CI 0.02-0.49\%). In both instances, the patient experienced new-onset neurological symptoms associated with the finding of a cyst-associated subdural hygroma on detected imaging. The rate of nonconcussive injury during sports participation was 2 per 1470 seasons of sports participation. Both patients who presented with subdural hygroma resulting from a sports injury had previously asymptomatic and untreated ACs.

Eighty patients completed at least 1 survey after their initial data were recorded and were included in a prospective registry, with a mean prospective follow-up duration of $15.9 \pm 8.8$ months. For these 80 patients, the mean age at survey was 9.0 years \pm 5.6 years. There were 61 boys and 19 girls; 12 were treated, and 52 participated in sports. The prospective group did not differ significantly from the retrospective group by sex $(\mathrm{p}=0.25)$, age $(\mathrm{p}=0.13)$, treatment status $(\mathrm{p}=0.89)$, or sports participation $(\mathrm{p}=0.35)$. During the follow-up period, 14 of these patients started participation in new sports after the initial consultation and 6 patients stopped participating in sports. One patient had a concussion during the follow-up interval. One patient in this group had a concussion during prospective follow-up. No other neurological injuries were noted in the prospective group.

\section{Traumatic Subdural Hygroma Case 1}

A 12-year-old girl began to experience headaches after heading a ball during a soccer game. The headaches persisted and she presented to the emergency department 2.5 weeks following onset of the headaches due to worsening symptoms including nausea and vomiting. A right middle fossa $\mathrm{AC}$ with an associated subdural hygroma was found on MRI (Fig. 3). On neurological examination her status was normal. We elected to attempt to treat this patient without surgery. Four weeks later, her headaches were 


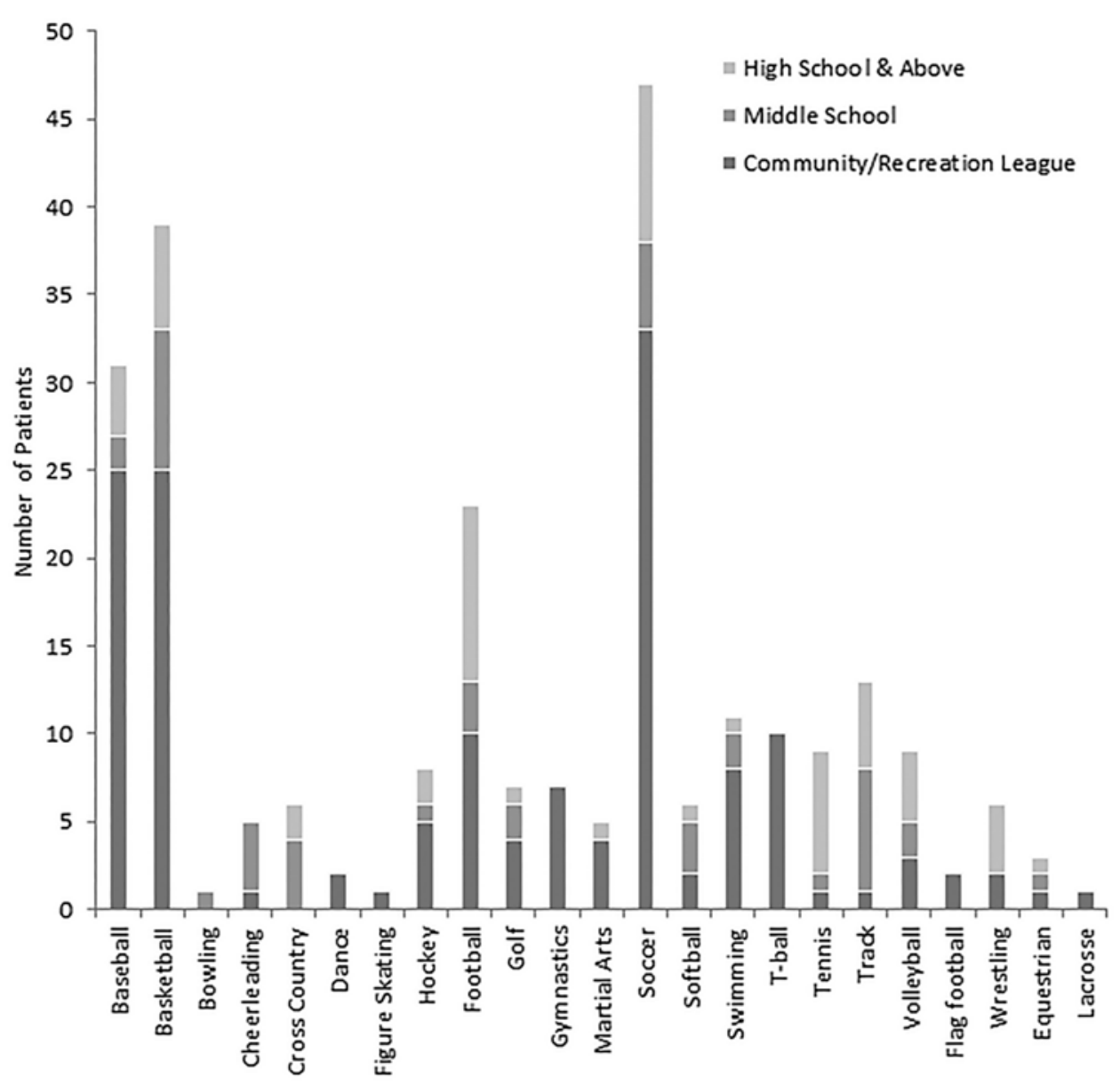

FIG. 1. Patient athletic participation by type of sport and level of activity $(n=112)$.

significantly improved and the hygroma was smaller on MRI. Her headaches resolved 3 months following the injury. Follow-up MRI at 3 months demonstrated complete resolution of the hygroma and no change to the appearance of the AC.

\section{Case 2}

A 16-year-old boy began to experience headaches 1 day after participating in a high school football game. The headaches worsened over the next several days and he was referred for neurosurgical evaluation. At the time of presentation to the neurosurgical clinic 2 weeks following the injury, he was asymptomatic and had a normal status on neurological examination. A right middle fossa $\mathrm{AC}$ and subdural hygroma were noted on brain MRI (Fig. 4). No surgical treatment was recommended. Follow-up imaging was performed 3 months following the injury and again 1 year following the injury. These studies demonstrated progressively decreasing size of the hygroma and the AC.

\section{Discussion}

Intracranial $\mathrm{AC}$ is a common reason for neurosurgical referral. With the increasing utilization of brain imaging, especially MRI, a large number of these lesions are now discovered incidentally. ${ }^{1,2,20,34,39,44,62}$ In our experience, care providers are frequently asked to provide guidance to patients and their families regarding what level of sports participation should be considered safe when harboring an AC. The American Academy of Pediatrics has periodically made recommendations for participation in sports. ${ }^{54}$ No recommendations were made in these statements regarding sports participation for patients with ACs, although the most recent report by this group suggests that any serious head abnormality should be evaluated prior to sports participation. ${ }^{54}$ Individual opinions vary widely, with some surgeons considering the presence of even an asymptomatic AC a contraindication or relative contraindication for participation in sports, ${ }^{5,10,51,59,69}$ while others permit a return to play in most cases. ${ }^{25,43,59}$ Tamburrini et al. ${ }^{59}$ surveyed 45 neurosurgeons on their management recommendation for an asymptomatic, incidentally discovered left middle fossa $\mathrm{AC}$ and found that $22.1 \%$ of the respondents would advise against participation in contact sports. Sports organizations are also divided on the issue. The Amateur Boxing Association of England will not allow athletes with known ACs to compete. ${ }^{17}$ On the other hand, at least one professional football player continued to play following diagnosis of a middle fossa $\mathrm{AC} .^{25}$

Several groups have examined incidental findings on 
TABLE 1. Cohort of 112 sports participants with ACs dichotomized by sport, level of competition, and number of concussions

\begin{tabular}{|c|c|c|c|c|c|c|c|c|}
\hline \multirow[b]{2}{*}{ Sport } & \multirow[b]{2}{*}{ Male† } & \multirow[b]{2}{*}{ Female† } & \multirow[b]{2}{*}{ Concussions } & \multicolumn{2}{|c|}{ Sports Participation* } & \multicolumn{3}{|c|}{ Level of Participation } \\
\hline & & & & No. of Months & No. of Seasons & $\begin{array}{c}\text { Community/Recreation } \\
\text { League }\end{array}$ & $\begin{array}{l}\text { Middle } \\
\text { School }\end{array}$ & $\begin{array}{l}\text { High School } \\
\text { \& Above }\end{array}$ \\
\hline Baseball & 35 & 4 & 0 & 380 & 127 & 25 & 2 & 4 \\
\hline Basketball & 30 & 9 & 1 & 362 & 121 & 25 & 8 & 6 \\
\hline Bowling & 3 & 1 & 0 & 143 & 48 & 0 & 1 & 0 \\
\hline Cheerleading & 1 & 4 & 0 & 45 & 15 & 1 & 4 & 0 \\
\hline Cross country & 6 & 1 & 0 & 48 & 16 & 0 & 4 & 2 \\
\hline Dance & 0 & 4 & 0 & 278 & 93 & 2 & 0 & 0 \\
\hline Equestrian & 0 & 3 & 0 & 51 & 17 & 1 & 1 & 1 \\
\hline Figure skating & 0 & 2 & 1 & 30 & 10 & 1 & 0 & 0 \\
\hline Flag football & 2 & 0 & 0 & 14 & 5 & 2 & 0 & 0 \\
\hline Football & 25 & 0 & 9 & 374 & 125 & 10 & 3 & 10 \\
\hline Golf & 6 & 0 & 0 & 36 & 12 & 4 & 2 & 1 \\
\hline Gymnastics & 1 & 7 & 0 & 83 & 28 & 7 & 0 & 0 \\
\hline Hockey & 6 & 2 & 1 & 78 & 26 & 5 & 1 & 2 \\
\hline Lacrosse & 1 & 0 & 0 & 3 & 1 & 1 & 0 & 0 \\
\hline Martial arts & 5 & 2 & 1 & 195 & 65 & 4 & 0 & 1 \\
\hline Motocross & 1 & 0 & 1 & 60 & 20 & & & \\
\hline Rugby & 1 & 0 & 0 & 3 & 1 & & & \\
\hline Skiing & 1 & 0 & 0 & 42 & 14 & & & \\
\hline Soccer & 43 & 15 & 3 & 1157 & 386 & 33 & 5 & 9 \\
\hline Softball & 0 & 6 & 0 & 149 & 50 & 2 & 3 & 1 \\
\hline Swimming & 9 & 5 & 0 & 429 & 143 & 8 & 2 & 1 \\
\hline T-ball & 10 & 0 & 0 & 45 & 15 & 10 & 0 & 0 \\
\hline Tennis & 4 & 6 & 0 & 66 & 22 & 1 & 1 & 7 \\
\hline Track & 10 & 4 & 0 & 97 & 32 & 1 & 7 & 5 \\
\hline Volleyball & 0 & 10 & 0 & 125 & 42 & 3 & 2 & 4 \\
\hline Wrestling & 6 & 0 & 1 & 117 & 39 & 2 & 0 & 4 \\
\hline Total & 206 & 85 & 18 & 4410 & 1473 & 148 & 46 & 58 \\
\hline
\end{tabular}

* Values represent cumulative participation.

† Some participants played multiple sports.

CT scans obtained in children following trauma. ${ }^{23,47,56}$ Ortega et al. ${ }^{47}$ found 7 intracranial ACs in 594 patients who underwent head CT following a head injury. Eskandary et al. ${ }^{23}$ reported on 7 patients with incidentally discovered AC among 3000 patients undergoing head CT for trauma,

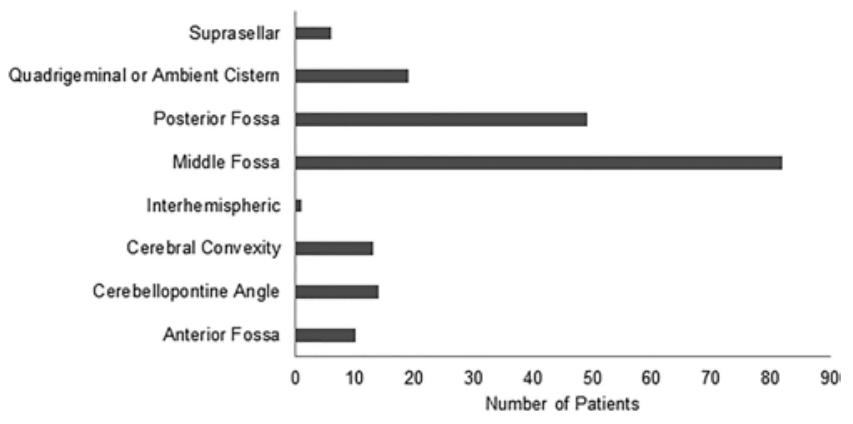

FIG. 2. AC distribution by location. and Rogers et al. ${ }^{56}$ found 79 intracranial cysts that were discovered incidentally on CT scans following traumatic injury as part of a large, multicenter trauma database. Although we believe that these case series were not designed to properly estimate the true imaging prevalence of ACs, it is worth noting that none of the patients in these case series with incidentally discovered ACs following trauma had any reported cyst-related hemorrhage or hygroma.

Several retrospective case series have found that patients with ACs will occasionally present with symptoms following a traumatic event, most often due to the development of a subdural hygroma. ${ }^{38,48}$ Posttraumatic subdural hygromas are thought to arise from a tear in the arachnoid membrane resulting in a one-way-valve mechanism that leads to the accumulation of CSF under abnormally elevated pressure. ${ }^{46}$ AC-associated hygromas may form when the outer cyst membrane tears as a result of trauma or surgical manipulation. $3,7,11-13,16,18,19,22,24,26,35,44,45,48,58,63,66,67$ Hygromas undoubtedly result in elevated intracranial pressure in some cases, and patients with a symptomatic 

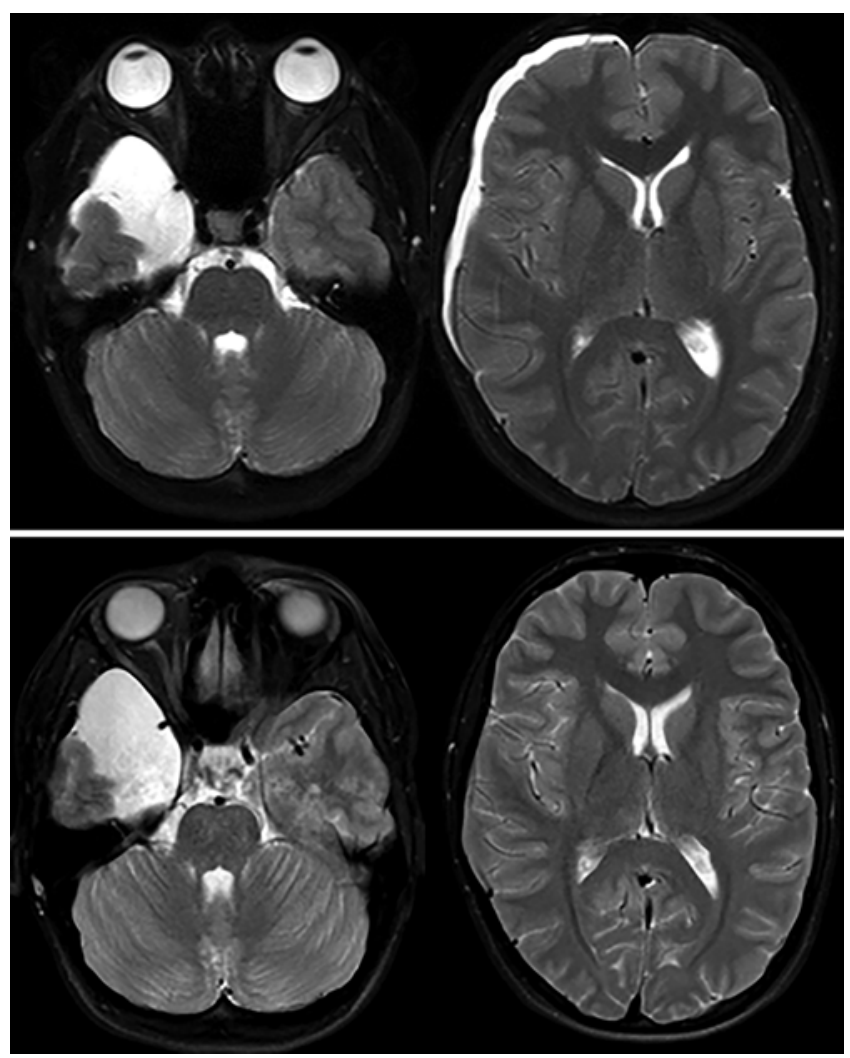

FIG. 3. Case 1. Axial T2-weighted MR images demonstrating a right middle fossa AC with an associated subdural hygroma at time of initial presentation (upper). Three months later (lower), the hygroma has resolved and the appearance of the cyst is unchanged.

hygroma will be more likely to present for evaluation than other patients with asymptomatic AC. ${ }^{15}$ For this reason, subdural hygromas would be expected to be overrepresented in most reported series of AC. Furthermore, most reported posttraumatic hygromas result from motor vehicle accidents, falls, or other trauma rather than sportsrelated injuries. $312,15,35,36,38,44,45,48,52,66$ Even given these limitations, however, it is clear that presentation of an AC with hygroma does occasionally result from sports participation. ${ }^{21,30,61}$ The relative rarity of such case reports in the literature suggests that the incidence of hygroma following sports injury is relatively rare.

A low incidence of sports-related hygroma is also supported by our own registry data. In our registry, 2 patients developed neurological symptoms from a subdural hygroma during sports participation. Both of these patients were included in our previous report on the management of subdural hygroma. In that series, 2 patients presented with subdural hygroma following sports participation and 6 patients presented with hygroma occurring either spontaneously or following other forms of trauma. ${ }^{38}$ In our practice, most patients with posttraumatic hygroma are managed without surgery, although surgery is occasionally required to treat patients with especially severe or persistent symptoms.

Many surgeons have advocated surgical treatment for AC-associated subdural hygroma. ${ }^{3,8,9,21,26,29,50,59}$ In our own practice, ${ }^{38}$ we have observed that patients with symptom-
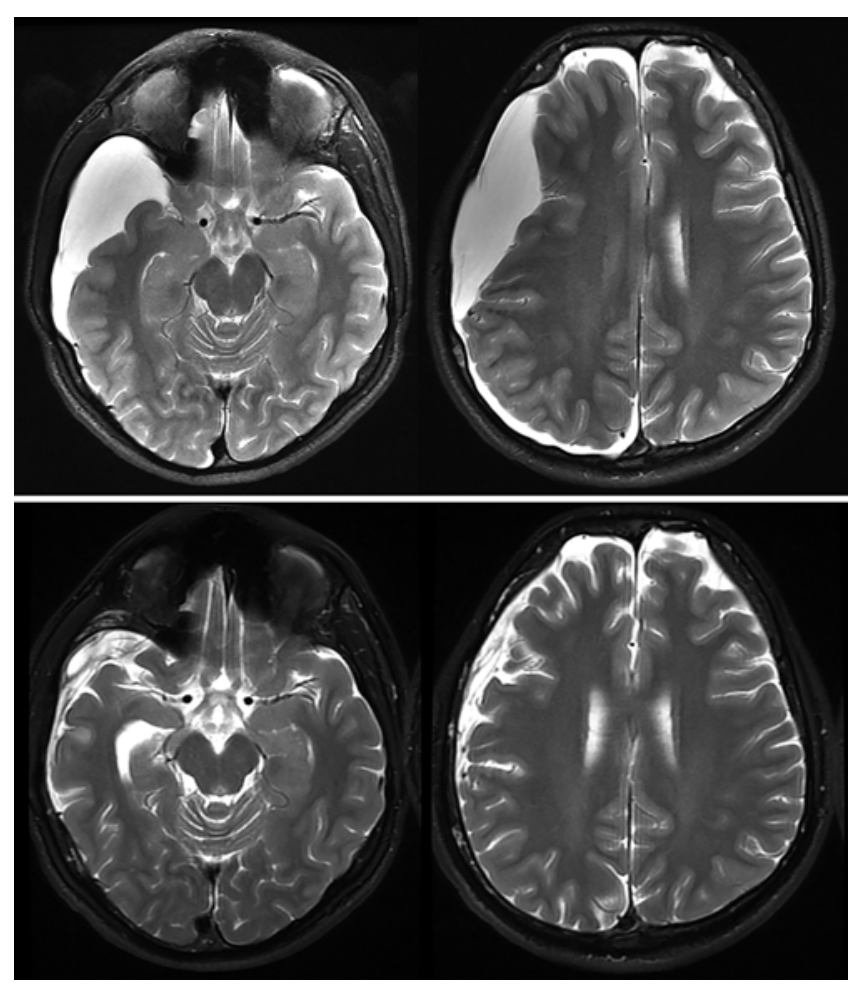

FIG. 4. Case 2. Axial T2-weighted MR images demonstrating a right middle fossa $\mathrm{AC}$ with associated subdural hygroma at time of initial presentation (upper). One year later (lower), the hygroma and $A C$ are both smaller.

atic AC-associated subdural hygromas will frequently experience a complete and lasting spontaneous resolution of their neurological symptoms if managed without surgery, even in cases with transient symptoms of elevated intracranial pressure. For this reason, we suggest that the decision to surgically treat symptomatic hygromas associated with ACs should be made carefully and only after the generally benign natural history of this condition is considered. Close clinical follow-up is required for symptomatic patients with cyst-associated hygroma who are managed without surgery. We recommend surgical treatment of AC-associated hygroma only for patients with especially severe presentations or whose symptoms are refractory to initial conservative management.

Hemorrhage into an AC is occasionally seen following trauma..$^{2,4,7,20,44,45,48,64}$ The potential for posttraumatic or spontaneous hemorrhage has even been used as a justification for prophylactic treatment of asymptomatic ACs by some neurosurgeons. ${ }^{59}$ These hemorrhages appear to be rare. We have previously reported on 309 consecutively managed children ${ }^{2}$ and 661 consecutively managed adults ${ }^{1}$ who presented to our institution with an intracranial AC; only 2 out of these 970 patients presented with a posttraumatic hemorrhage into the $\mathrm{AC}$ or the adjacent subdural space. Wester and Helland ${ }^{64}$ found 11 patients with chronic hematoma among 241 patients who were evaluated for AC. We suspect that patients with hematoma might be more likely to present for imaging and evaluation and that these series have the potential to overestimate the 
incidence of hemorrhage within ACs. Importantly, most previously reported posttraumatic hemorrhages resulted from falls or traffic accidents ${ }^{2,15,44,45,48,64}$ rather than athletic participation. . $^{17,20,31-33,51,61}$ Sports that have been implicated in AC-associated hematomas include soccer, ${ }^{17,32,51}$ football, ${ }^{33}$ basketball, ${ }^{60}$ boxing, ${ }^{55}$ Taekwondo, ${ }^{61}$ and even a "head-shaking competition." 31 There were no patients in our sports registry who had hemorrhage within their $\mathrm{AC}$ or the adjacent subdural space as a result of a sportsrelated injury. We believe that hemorrhage into an $\mathrm{AC}$ is a possible but rare complication of athletic participation for those patients with ACs. Furthermore, hemorrhages associated with ACs are associated with good long-term outcomes in most cases. ${ }^{1,2,20,32,33,44,45,48,51}$ We do not think that the rare incidence of these hemorrhages can justify "prophylactic" surgical treatment or restriction from athletic participation in most cases.

As concussions are a common injury among all athletes, it is not surprising that we have found that some individuals with ACs will have a concussion during sports participation. The concussion incidence is not higher than should be anticipated in the general pediatric population. ${ }^{6,37,40,57}$ Concussion rates vary according to type of sport. Recent studies have found concussion rates of $6.7 \%-25 \%$ per season for all participants in high school football or hockey,,$^{14,27,41,65} 2 \%$ per season for basketball, ${ }^{28}$ and $1 \%$ per season for baseball. ${ }^{49}$ As expected, we found a higher concussion incidence in contact sports than noncontact sports.

Prior reports that examined the rate of sports injury have used several different metrics. Many groups report on injury rates according to injuries per 1000 athlete exposures using the National High School Sports-Related Injury Surveillance System's data collection tool, the High School Reporting Information Online..$^{37,40,53,57}$ In these reports, an athlete exposure is 1 athlete participating in 1 practice or competition. ${ }^{53}$ The nature of our registry data did not allow for examination of individual athlete exposures in the present study without making assumptions about the number of exposures in each time period. Instead, we chose to record injury rates and concussion rates according to events per 1000 sports seasons (with a season defined as a 3-month period for this study) or sports months. Reporting injury rates per season is an accepted method of reporting injury rates, $14,27,28,41,49,65$ and we think it is a more precise incidence unit given our available data.

There are several important limitations to this analysis. Although the registry was accumulated prospectively, most of the injuries and sports participation had occurred prior to data entry and should be considered retrospective. Although we treat a small minority of ACs surgically in our practice,,$^{1,2}$ surgical patients are overrepresented in this cohort. This is most likely a result of follow-up patterns in our practice; surgically treated patients tend to be followed for longer durations than those not treated surgically. Those with 2 or more surveys were included in the prospective group. We generally see all AC patients in return consultation without regard to patient age, cyst size, or cyst location. In our practice, patients are not advised to avoid sports. Therefore, the finding of no significant differences in the prospective and retrospective groups with respect to age, cyst size, cyst location, or rate of sports participa- tion was expected. Patients or their families were asked to recall details of participation in sports and any history of sports-related injury. Some injuries, it is possible, may not have been recorded because the patient or family did not remember athletic participation or an injury event. We are inclined to believe that recall bias would be more likely to affect the level of athletic participation rather than injury information because families, we believe, are more likely to recall significant injuries. Concussion events and other injury episodes were self-reported. An event was considered a concussion if the event that the patient or family reported was considered consistent with this diagnosis. ${ }^{42}$ All patients were referred for neurosurgical evaluation, and this group may not be representative of all patients with an AC who are not referred for subspecialty care. We do not believe that our selected group of AC patients should have any decreased risk of sports injury compared with a typical group of AC patients referred for pediatric neurosurgery evaluation.

Older patients participating in collision sports at a high level should be expected to have a higher injury rate for participants with or without an AC. Our data do not show a high rate of injury, even for this group. Nevertheless, it must be acknowledged that participants in activities associated with the highest sports injury rates comprised a small minority of our cohort. Only 23 of our patients were teenagers participating in contact sports. More information on this highest-risk group is needed before any firm conclusions regarding the relative safety of AC patient participation in these types of activities can be made. Finally, since hygroma was rarely noted in our registry, we cannot comment on particular characteristics such as cyst size ${ }^{15}$ that may make AC-associated hygroma or hematoma more likely.

To call an activity "safe" is to make a judgment relative to some subjective standard for a level of acceptable safety. No contact sport is truly safe if the standard is one of absolute safety-that is to say, that no injuries will ever occur. Such a strict standard is not held for the general population, and, in our opinion, it should not be held for patients with AC. If it is agreed that the absolute safety standard is impractical, then we are left to determine how safe is "safe enough." Continued prospective acquisition of athletic participation and injury data will lead to better definitions of risk in the future.

\section{Conclusions}

We have reported on 185 patients with $\mathrm{AC}$ who have been enrolled in a sports participation registry and who were found to have no permanent, significant injuries. We conclude that sports-related neurological injuries for patients with $\mathrm{AC}$ are rare. On the basis of these data, we believe that we are justified in continuing our current permissive practice. We hope that the registry data that we have presented will reassure patients and care providers that sports participation is safe for patients with $\mathrm{AC}$ in most cases.

\section{Acknowledgments}

We would like to thank Holly Wagner for providing editorial assistance. 


\section{References}

1. Al-Holou WN, Terman S, Kilburg C, Garton HJ, Muraszko KM, Maher CO: Prevalence and natural history of arachnoid cysts in adults. J Neurosurg 118:222-231, 2013

2. Al-Holou WN, Yew AY, Boomsaad ZE, Garton HJ, Muraszko KM, Maher CO: Prevalence and natural history of arachnoid cysts in children. J Neurosurg Pediatr 5:578-585, 2010

3. Albuquerque FC, Giannotta SL: Arachnoid cyst rupture producing subdural hygroma and intracranial hypertension: case reports. Neurosurgery 41:951-956, 1997

4. Auer LM, Gallhofer B, Ladurner G, Sager WD, Heppner F, Lechner H: Diagnosis and treatment of middle fossa arachnoid cysts and subdural hematomas. J Neurosurg 54:366369, 1981

5. Bailes JE: Chronic subdural hematoma complicating arachnoid cyst secondary to soccer-related head injury: case report: in reply. Neurosurgery 53:243, 2003 (Letter)

6. Bailes JE, Cantu RC: Head injury in athletes. Neurosurgery 48:26-46, 2001

7. Bilginer B, Onal MB, Oguz KK, Akalan N: Arachnoid cyst associated with subdural hematoma: report of three cases and review of the literature. Childs Nerv Syst 25:119-124, 2009

8. Bristol RE, Albuquerque FC, McDougall C, Spetzler RF: Arachnoid cysts: spontaneous resolution distinct from traumatic rupture. Case report. Neurosurg Focus 22(2):E2, 2007

9. Cakir E, Kayhankuzeyli, Sayin OC, Peksoylu B, Karaarslan G: Arachnoid cyst rupture with subdural hygroma: case report and literature review. Neurocirugia (Astur) 15:72-75, 2004

10. Cantu RC: Comment on "Chronic subdural hematoma complicating arachnoid cyst secondary to soccer-related head injury: case report.” Neurosurgery 50:197, 2002

11. Cayli SR: Arachnoid cyst with spontaneous rupture into the subdural space. Br J Neurosurg 14:568-570, 2000

12. Choong CT, Lee SH: Subdural hygroma in association with middle fossa arachnoid cyst: acetazolamide therapy. Brain Dev 20:319-322, 1998

13. Choux M, Raybaud C, Pinsard N, Hassoun J, Gambarelli D: Intracranial supratentorial cysts in children excluding tumor and parasitic cysts. Childs Brain 4:15-32, 1978

14. Collins M, Lovell MR, Iverson GL, Ide T, Maroon J: Examining concussion rates and return to play in high school football players wearing newer helmet technology: a three-year prospective cohort study. Neurosurgery 58:275-286, 2006

15. Cress M, Kestle JR, Holubkov R, Riva-Cambrin J: Risk factors for pediatric arachnoid cyst rupture/hemorrhage: a casecontrol study. Neurosurgery 72:716-722, 2013

16. Cullis PA, Gilroy J: Arachnoid cyst with rupture into the subdural space. J Neurol Neurosurg Psychiatry 46:454-456, 1983

17. Demetriades AK, McEvoy AW, Kitchen ND: Subdural haematoma associated with an arachnoid cyst after repetitive minor heading injury in ball games. Br J Sports Med 38:E8, 2004

18. Di Rocco C: Sylvian fissure arachnoid cysts: we do operate on them but should it be done? Childs Nerv Syst 26:173-175, 2010

19. Dodd RL, Barnes PD, Huhn SL: Spontaneous resolution of a prepontine arachnoid cyst. Case report and review of the literature. Pediatr Neurosurg 37:152-157, 2002

20. Domenicucci M, Russo N, Giugni E, Pierallini A: Relationship between supratentorial arachnoid cyst and chronic subdural hematoma: neuroradiological evidence and surgical treatment. J Neurosurg 110:1250-1255, 2009

21. Donaldson JW, Edwards-Brown M, Luerssen TG: Arachnoid cyst rupture with concurrent subdural hygroma. Pediatr Neurosurg 32:137-139, 2000

22. Ergün R, Okten AI, Beşkonakli E, Anasiz H, Ergüngör F,
Taşkin Y: Unusual complication of arachnoid cyst: spontaneous rupture into the subdural space. Acta Neurochir (Wien) 139:692-694, 1997

23. Eskandary H, Sabba M, Khajehpour F, Eskandari M: Incidental findings in brain computed tomography scans of 3000 head trauma patients. Surg Neurol 63:550-553, 2005

24. Galassi E, Piazza G, Gaist G, Frank F: Arachnoid cysts of the middle cranial fossa: a clinical and radiological study of 25 cases treated surgically. Surg Neurol 14:211-219, 1980

25. Gamradt SC, Brophy R, Barnes R, Birchansky S, Rodeo SA, Warren RF, et al: Incidental findings in cerebral imaging: arachnoid cyst in a professional football player. Clin J Sport Med 18:97-99, 2008

26. Gelabert-González M, Fernández-Villa J, Cutrín-Prieto J, Garcìa Allut A, Martínez-Rumbo R: Arachnoid cyst rupture with subdural hygroma: report of three cases and literature review. Childs Nerv Syst 18:609-613, 2002

27. Gerberich SG, Priest JD, Boen JR, Straub CP, Maxwell RE: Concussion incidences and severity in secondary school varsity football players. Am J Public Health 73:1370-1375, 1983

28. Gomez E, DeLee JC, Farney WC: Incidence of injury in Texas girls' high school basketball. Am J Sports Med 24:684-687, 1996

29. Goswami P, Medhi N, Sarma PK, Sarmah BJ: Case report: Middle cranial fossa arachnoid cyst in association with subdural hygroma. Indian J Radiol Imaging 18:222-223, 2008

30. Gupta R, Vaishya S, Mehta VS: Arachnoid cyst presenting as subdural hygroma. J Clin Neurosci 11:317-318, 2004

31. Hopkin J, Mamourian A, Lollis S, Duhaime T: The next extreme sport? Subdural haematoma in a patient with arachnoid cyst after head shaking competition. Br J Neurosurg 20:111-113, 2006

32. Kawanishi A, Nakayama M, Kadota K: Heading injury precipitating subdural hematoma associated with arachnoid cysts - two case reports. Neurol Med Chir (Tokyo) 39:231233, 1999

33. Kertmen H, Gürer B, Yilmaz ER, Sekerci Z: Chronic subdural hematoma associated with an arachnoid cyst in a juvenile taekwondo athlete: a case report and review of the literature. Pediatr Neurosurg 48:55-58, 2012

34. Kim BS, Illes J, Kaplan RT, Reiss A, Atlas SW: Incidental findings on pediatric MR images of the brain. AJNR Am J Neuroradiol 23:1674-1677, 2002

35. Kulali A, von Wild K: Post-traumatic subdural hygroma as a complication of arachnoid cysts of the middle fossa. Neurosurg Rev 12 (Suppl 1):508-513, 1989

36. Lesoin F, Dhellemmes P, Rousseaux M, Jomin M: Arachnoid cysts and head injury. Acta Neurochir (Wien) 69:43-51, 1983

37. Lincoln AE, Caswell SV, Almquist JL, Dunn RE, Norris JB, Hinton RY: Trends in concussion incidence in high school sports: a prospective 11-year study. Am J Sports Med 39:958-963, 2011

38. Maher CO, Garton HJ, Al-Holou WN, Trobe JD, Muraszko KM, Jackson EM: Management of subdural hygromas associated with arachnoid cysts. J Neurosurg Pediatr 12:434-443, 2013

39. Maixner VJ, Besser M, Johnston IH: Pseudotumor syndrome in treated arachnoid cysts. Childs Nerv Syst 8:207-210, 1992

40. Marar M, McIlvain NM, Fields SK, Comstock RD: Epidemiology of concussions among United States high school athletes in 20 sports. Am J Sports Med 40:747-755, 2012

41. McCrea M, Hammeke T, Olsen G, Leo P, Guskiewicz K: Unreported concussion in high school football players: implications for prevention. Clin J Sport Med 14:13-17, 2004

42. McCrory P, Meeuwisse W, Johnston K, Dvorak J, Aubry M, Molloy M, et al: Consensus statement on Concussion in Sport 
3rd International Conference on Concussion in Sport held in Zurich, November 2008. Clin J Sport Med 19:185-200, 2009

43. Miele VJ, Bailes JE, Martin NA: Participation in contact or collision sports in athletes with epilepsy, genetic risk factors, structural brain lesions, or history of craniotomy. Neurosurg Focus 21(4):E9, 2006

44. Mori K, Yamamoto T, Horinaka N, Maeda M: Arachnoid cyst is a risk factor for chronic subdural hematoma in juveniles: twelve cases of chronic subdural hematoma associated with arachnoid cyst. J Neurotrauma 19:1017-1027, 2002

45. Mori T, Fujimoto M, Sakae K, Sakakibara T, Shin H, Yamaki $\mathrm{T}$, et al: Disappearance of arachnoid cysts after head injury. Neurosurgery 36:938-942, 1995

46. Naffziger HC: Subdural fluid accumulations following head injury. JAMA 82:1751-1752, 1924

47. Ortega HW, Vander Velden H, Reid S: Incidental findings on computed tomography scans in children with mild head trauma. Clin Pediatr (Phila) 51:872-876, 2012

48. Parsch CS, Krauss J, Hofmann E, Meixensberger J, Roosen $\mathrm{K}$ : Arachnoid cysts associated with subdural hematomas and hygromas: analysis of 16 cases, long-term follow-up, and review of the literature. Neurosurgery 40:483-490, 1997

49. Pasternack JS, Veenema KR, Callahan CM: Baseball injuries: a Little League survey. Pediatrics 98:445-448, 1996

50. Poirrier AL, Ngosso-Tetanye I, Mouchamps M, Misson JP: Spontaneous arachnoid cyst rupture in a previously asymptomatic child: a case report. Eur J Paediatr Neurol 8:247251, 2004

51. Prabhu VC, Bailes JE: Chronic subdural hematoma complicating arachnoid cyst secondary to soccer-related head injury: case report. Neurosurgery 50:195-198, 2002

52. Rajesh A, Bramhaprasad V, Purohit AK: Traumatic rupture of arachnoid cyst with subdural hygroma. J Pediatr Neurosci 7:33-35, 2012

53. Rechel JA, Yard EE, Comstock RD: An epidemiologic comparison of high school sports injuries sustained in practice and competition. J Athl Train 43:197-204, 2008

54. Rice SG: Medical conditions affecting sports participation. Pediatrics 121:841-848, 2008

55. Robles LA, Hernandez V: Subdural and intracystic haematomas in an arachnoid cyst secondary to a boxing injury. Inj Extra 37:375-378, 2006

56. Rogers AJ, Maher CO, Schunk JE, Quayle K, Jacobs E, Lichenstein $\mathrm{R}$, et al: Incidental findings in children with blunt head trauma evaluated with cranial CT scans. Pediatrics 132:e356-e363, 2013

57. Rosenthal JA, Foraker RE, Collins CL, Comstock RD: National high school athlete concussion rates from 2005-2006 to 2011-2012. Am J Sports Med 42:1710-1715, 2014

58. Sener RN: Arachnoid cysts associated with post-traumatic and spontaneous rupture into the subdural space. Comput Med Imaging Graph 21:341-344, 1997

59. Tamburrini G, Dal Fabbro M, Di Rocco C: Sylvian fissure arachnoid cysts: a survey on their diagnostic workout and practical management. Childs Nerv Syst 24:593-604, 2008 (Erratum in Childs Nerv Syst 24:635, 2008)

60. Tsuzuki N, Katoh H, Ohtani N: Chronic subdural hematoma complicating arachnoid cyst secondary to soccer-related head injury: case report. Neurosurgery 53:242-243, 2003 (Letter)

61. Vigil DV, DiFiori JP, Puffer JC, Peacock WJ: Arachnoid cyst and subdural hygroma in a high school football player. Clin J Sport Med 8:234-237, 1998

62. Weber F, Knopf H: Incidental findings in magnetic resonance imaging of the brains of healthy young men. J Neurol Sci 240:81-84, 2006

63. Weinberg PE, Flom RA: Intracranial subarachnoid cysts. Radiology 106:329-333, 1973

64. Wester K, Helland CA: How often do chronic extra-cerebral haematomas occur in patients with intracranial arachnoid cysts? J Neurol Neurosurg Psychiatry 79:72-75, 2008

65. Williamson IJ, Goodman D: Converging evidence for the under-reporting of concussions in youth ice hockey. $\mathbf{B r} \mathbf{J}$ Sports Med 40:128-132, 2006

66. Yamanouchi Y, Someda K, Oka N: Spontaneous disappearance of middle fossa arachnoid cyst after head injury. Childs Nerv Syst 2:40-43, 1986

67. Yokoyama K, Tonami N, Kimura M, Kinoshita A, Aburano T, Hisada K: Scintigraphic demonstration of intracranial communication between arachnoid cyst and associated subdural hematoma. Clin Nucl Med 14:350-353, 1989

68. Zar JH: Biostatistical Analysis. Upper Saddle River, NJ: Prentice Hall, 1996, pp 524-525

69. Zeng T, Shi SS, Lin YF: Chronic subdural hematoma associated with sylvian arachnoid cyst in juvenile athletes: report of two cases and literature review. Chin J Traumatol 14:174177,2011

\section{Disclosures}

The authors report no conflict of interest concerning the materials or methods used in this study or the findings specified in this paper.

\section{Author Contributions}

Conception and design: Maher. Acquisition of data: all authors. Analysis and interpretation of data: Maher, J Strahle, Selzer, Geh, Srinivasan, M Strahle, Martinez-Sosa, Muraszko, Garton. Drafting the article: Maher, J Strahle, Geh, Selzer. Critically revising the article: Maher, Garton, Strahle. Reviewed submitted version of manuscript: all authors. Approved the final version of the manuscript on behalf of all authors: Maher. Statistical analysis: Geh, Strahle. Study supervision: Maher.

\section{Correspondence}

Cormac O. Maher, Department of Neurosurgery, University of Michigan, 1500 E. Medical Center Dr., Rm. 3552 Taubman Center, Ann Arbor, MI 48109-5338. email: cmaher@med.umich. edu. 